colonies in Alsace are vanishing. It has been stated (Bowen) that a pair built on the roof of St. Giles Cathedral, Edinburgh, in 1466, but did not return.

\section{Migration of Storks}

SToRks nesting east of the River Elbe have been found to use the Asia Minor route when migrating, and those nesting west of the Elbe are stated to take the route through Spain. The winter quarters of European storks is Natal and near the Cape of Good Hope, South Africa, and Danish storks have been described using the route through Germany, Czechoslovakia and Hungary, to cross the Bosphorus to Asia Minor, but evidence of ringed birds reaching the Nile across the Mediterranean or through Palestine seems lacking, though prior to ringing, Shaw has described the annual migration from Egypt over Mount Carmel as occupying three hours. The Danish storks leave in late August and arrive at their winter quarters, 7,500 miles away, in about two months, though the return migration is quicker. Of 125 young storks bred at Rossitten, on the Asia Minor route, and released at Essen, on the France and Spain route, on September 12, to see whether the migration route is hereditary, reports indicated many following a south-eastern route, though two have been shot on the Loire, in France.

\section{International Society of Leather Trades Chemists}

THE bi-annual meeting of the International Society of Leather Trades Chemists was held at the Colonial Institute, Amsterdam, on September 18-21 in conjunction with the I.V.L.I.C., the president, Mr. F. C. Thompson, being in the chair. The president elect for 1934-35 is M.C. R. Loos (France), and the 1935 Conference is to be held at Brussels at the invitation of the Belgian Section. During the proceedings, Prof. E. Stiasny (Darmstadt) was unanimously elected an honorary member of the Society, in recognition of his international scientific services. In his presidential address, Mr. F. C. Thompson dealt with the subject of $p \mathrm{H}$ determination, at the conclusion of which the Society nominated a special commission to consider this subject, particularly from the point of view of the leather and allied industries. The technical and scientific agenda comprised some thirty-eight contributions, the opening paper being by Prof. H. R. Kruyt (University of Utrecht) on "The Colloid Chemistry of Collagen and Gelatin". In the light of de Jong's theory of complex coacervations, collagen was regarded as a complex coacervate, this theory being discussed also from the points of view of the histologist and embryologist. At a special session with the International Tanners' Council, a film was shown on the Warble fly, followed by a lecture by Prof. M. Bergmann (Dresden) on "Hide and Skin Preservation". Among other papers presented were "The Structure of Collagen Fibres" by Dr. A. Kuntzel, "Characteristics of Vegetable Tanning", Dr. F. Stather, "Some Problems of Two Bath Chrome Tanning", Prof. E. Stiasny, C. Riess and A. Papayannis, "Estimation of Acid in Chrome Leather", C. Riess and A.
Papayannis, "X-ray Spectrograph of Albumin with Relation to Collagen and Gelatin" and "Studies on Mutarotation of Gelatin" by Prof. J. R. Katz. "Histology of the Corium and Grain of Hide", by Dr. G. C. Heringa, "On the Theory of Leather Dyeing" by Prof. E. Elod. A number of other papers related to leather technology.

\section{Quality of Sound Reproduction}

The inaugural meeting of the 1933-34 session of the British Radio Institution was held at King's College, London, on September 22, when Dr. L. E. C. Hughes gave a lantern lecture entitled "Reproduction of Sound via Radio". Dr. Hughes introduced his topic from the system point of view, indicating that many mistakes have been made in the past in concentrating too closely on particular details of broadcasting, forgetting that other sound reproducing systems have overlapped and provided information which could be turned to use in the system under discussion. It is most desirable that the general conditions required for good reproduction of sound should be applied uniformly not only to sound-systems as a whole but also to the component parts. In this way, all departures from the ideal criteria for reproduction can be assessed. Of greatest importance are the response curves of microphones and loud-speaking receivers, not only the response relating to the actual power output as compared with the input power, but also the distribution curves indicating the response of the units in different directions. Dr. Hughes outlined the methods of sound measurement which are in use for determining these response curves. At the moment, the basic calibrations by the Rayleigh disc and the thermophone are relied upon. The great difficulty is to ascertain what tolerances from the ideal criterion can be permitted. At present there is no standard loud-speaking receiver, whereas for head-phone reception of reproduced sound, the moving-coil receiver has long been a standard and is accepted internationally. The hope was expressed that a standard for radiated sound reproduction would be soon realised and a large amount of guess-work in estimating the quality of reproduction eliminated.

\section{Astrophysical Observations in the Southern Hemisphere}

Mr. A. G. C. Crust, Meteorological Office, Wellington, New Zealand, has written directing attention to the advantages offered by certain sites in that country for the establishment of a large astrophysical observatory. Since statistical observations of the distribution of the various astrophysical objects over the sky are necessarily incomplete without observations of the southern skies, it is vitally important for the progress of astrophysics that a really large reflector should be established somewhere in the southern hemisphere. The only reason for the delay is, of course, the expense of erecting and maintaining an observatory with a large telescope, which would be considerable. So far, no private person or public institution has come forward with an offer to finance such an enterprise; instead, an extremely insular 